\title{
A Rare Case of Functional Ectopic Hyperthyroidism: Struma Ovarii
}

\author{
${ }^{1}$ Indu Lata, ${ }^{2}$ Deepa Kapoor
}

\begin{abstract}
Struma ovarii (SO) is a rare special type of monodermal teratoma of ovary that predominantly consists of thyroid tissue (> $50 \%$ ). In only 5 to $20 \%$ of cases hyperthyroidism is seen due to functional SO. We are reporting here a case of unilateral benign cystic SO in a 50-year-old postmenopausal lady presented with pain and heaviness in lower abdomen without any signs and symptoms of hyperthyroidism. Pelvic ultrasonogram showed right side tubo-ovarian mass and was planned for laparotomy. In preoperative investigation subclinical hyperthyroidism was diagnosed. Abdominal exploration showed cystic mass lesion in right ovary. She underwent total abdominal hysterectomy with bilateral salpingo-oophorectomy. Histopathological examination diagnosed the mass as benign cystic SO. Patient became euthyroid after surgical removal of tumor.
\end{abstract}

Keywords: Hyperthyroidism, Monodermal teratoma, Struma ovarii.

How to cite this article: Lata I, Kapoor D. A Rare Case of Functional Ectopic Hyperthyroidism: Struma Ovarii. World J Endoc Surg 2016;8(3):212-213.

\section{Source of support: Nil}

Conflict of interest: None

\section{INTRODUCTION}

Struma ovarii (SO) is a variant of dermoid tumors of ovary that consists mainly of thyroid tissue. ${ }^{1}$ It accounts for about $2 \%$ of all ovarian germ cell tumors and are predominantly found in women of 40 to 60 years of age. ${ }^{2}$ In approximately $95 \%$ of cases, $\mathrm{SO}$ is benign, occupying $>50 \%$ of the ovarian mass. ${ }^{3-5}$ Thyroid tissue in the teratoma can exhibit all histological and pathological patterns of normal thyroid epithelium. Immunohisto-

\footnotetext{
${ }^{1}$ Associate Professor, ${ }^{2}$ Consultant

${ }^{1}$ Department of Maternal and Reproductive Health, Sanjay Gandhi Postgraduate Institute of Medical Sciences, Lucknow Uttar Pradesh, India

${ }^{2}$ Department of Obstetrics and Gynecology, Sanjay Gandhi Postgraduate Institute of Medical Sciences, Lucknow, Uttar Pradesh, India

Corresponding Author: Indu Lata, Associate Professor Department of Maternal and Reproductive Health, Sanjay Gandhi Postgraduate Institute of Medical Sciences, Lucknow Uttar Pradesh, India, Phone: +918004904523, e-mail: drindusandeep@gmail.com
}

chemical staining for thyroglobulin may be required to identify the cells' origin. Most of these tumors are asymptomatic, and diagnosed after surgery of a pelvic mass. ${ }^{6,7}$ Because of the rarity of the tumor, only a few reports with detailed data on thyroid function of the patient have been published.

\section{CASE REPORT}

A 50-year-old postmenopausal lady presented with history of lower abdominal pain and heaviness for 3 months. Pelvic ultrasonogram revealed $6.9 \times 5.7 \times 5.6 \mathrm{~cm}$ complex thick wall right ovarian cyst or tubo-ovarian mass. Patient was investigated for routine systemic blood investigation and CA-125 tumor marker that was within limit. She was planned for total abdominal hysterectomy with bilateral salpingo-oophorectomy. In preoperative investigations she was found as a case of subclinical hyperthyroidism. The Tc-99m-pertechnetate thyroid scan was suggestive of normal functioning thyroid scan. She had no thyromegaly. Laboratory work-up showed the following results. Her thyroid profile serum $\mathrm{T}_{3}=2.1 \mathrm{nmol} / \mathrm{L}$, $\mathrm{T}_{4}=111 \mathrm{nmol} / \mathrm{L}$, and thyroid stimulating hormone $(\mathrm{TSH})$ was $0.03 \mathrm{IU} / \mathrm{mL}$. These results showed normal thyroxin levels and decreased TSH levels. The values are indicative of subclinical hyperthyroidism. The rest of blood investigations and chest $X$-ray were normal. The abdominal hysterectomy with bilateral salpingo-oophorectomy was done under regional anesthesia. Intraoperative and immediate postoperative period was uneventful. Gross examination of the specimen showed uterus, cervix and tubes, and left ovary were normal. The cystic right ovary measured $5 \times 6 \times 3 \mathrm{~cm}$, while cut section showed multiloculated cyst filled with serous fluid. Cyst was thin wall without any solid areas or growth.

On microscopic examination of the cyst wall shows that it was composed of fibrous tissue lined by flattened epithelium. Foci of thyroid follicles were seen in cyst wall. No other component of mature teratoma was seen. No atypical cells were seen. Hence, it was diagnosed as benign cystic $\mathrm{SO}$ right ovary. Thus, our case was a functional $\mathrm{SO}$ with subclinical hyperthyroidism. Functional SO is very rare, accounting for only 5 to $8 \%$ of cases. Postoperative period was uneventful. All the signs and symptoms disappeared rapidly after surgical removal of 
tumor. She became euthyroid after a month of treatment with antithyroid drugs. Six months of follow-up showed no recurrence.

\section{DISCUSSION}

Struma ovarii represents 0.3 to $1 \%$ of all ovarian neoplasms. ${ }^{8}$ Kempers et $\mathrm{al}^{1}$ described three clinical situations for SO: Asymptomatic, ascitic, and thyrotoxic. Approximately 5 to $20 \%$ of struma produce significant amounts of thyroid hormones and cause thyrotoxicosis. ${ }^{9,10}$ The diagnosis should be considered in any patient with thyrotoxicosis, low radioiodine uptake over the thyroid, and a pelvic mass. Thyroiditis is the most common cause of nonvisualization of the cervical thyroid gland during radioiodine or pertechnetate scintigraphy but associated with hypothyroidism. So when cervical uptake is negative and there is presence of hyperthyroidism, radionuclide imaging of the pelvis should be performed. ${ }^{10}$

Struma ovarii should be included in the differential diagnosis of ovarian tumors when magnetic resonance imaging (MRI) shows a multicystic tumor with a solid component, a multilobulated surface with presence of viscid gelatinous material. ${ }^{11}$ Confirmatory diagnosis is made by correlation of pathological, clinical, and radiological examination. Malignant SO is very rare and seen only in larger tumors with features of atypia, capsular invasion, metastasis, and recurrence. ${ }^{12}$ Thyroid carcinoma metastatic to ovary should be ruled out before diagnosing a malignant SO. Surgical resection of the tumor is the treatment of choice for benign SO. Total abdominal hysterectomy with salpingo-oophorectomy and adjuvant radio iodine therapy is successful in treating malignant struma with metastatic involvement. Antithyroid drugs can be used preoperatively to ameliorate thyrotoxic symptoms and signs. $\beta$-adrenergic blocking agents combined with iodine, ipodate, or iopanoic acid to block the $\mathrm{T}_{4}$ to $\mathrm{T}_{3}$ conversion may be used in addition to thioamides to permit early surgery. ${ }^{10}$
Functional SO is difficult to diagnose and it is one of the differential diagnosis for hyperthyroidism in postmenopausal female. Diagnosis of SO is made easy with clinical suspicion and by following the investigations like thyroid profile, pelvic ultrasonogram, and radioiodine scan.

\section{REFERENCES}

1. Kempers RD, Dockerty MB, Hoffman DL, Bartholomew LG. Struma ovarii: ascitic, hyperthyroid, and asymptomatic syndromes. Ann Intern Med 1970 Jun;72(6):883-893.

2. Rotman-Pikielny P, Reynolds JC, Barker WC, Yen PM, Skarulis MC, Sarlis NJ. Recombinant human thyrotropin for the diagnosis and treatment of a highly functional metastatic struma ovarii. J Clin Endocrinol Metab 2000 Jan;85(1):237-244.

3. Bozkurt NC, Karbek B, Ozkaya EC, Cakal E, Delibaşi T. Struma ovarii presenting with Hashimoto's thyroiditis: a case report. J Med Case Rep 2011 Dec 12;5:572.

4. Ezon I, Zilbert N, Pinkney L, Wei JJ, Malik R, Nadler EP. A large struma ovarii tumor removed via laparoscopy in a 16-year-old adolescent. J Pediatr Surg 2007 Aug;42(8):E19-E22.

5. Matsuda K, Maehama T, Kanazawa K. Malignant struma ovarii with thyrotoxicosis. Gynecol Oncol 2001 Sep;82(3): 575-577.

6. Yoo SC, Chang KH, Lyu MO, Chang SJ, Ryu HS, Kim HS. Clinical characteristics of struma ovarii. J Gynecol Oncol 2008 Jun;19(2):135-138.

7. Shen J, Xia X, Lin Y, Zhu W, Yuan J. Diagnosis of struma ovarii with medical imaging. Abdom Imaging 2011 Oct;36(5): 627-631.

8. Ayhan A, Yanik F, Tuncer R, Tuncer ZS, Ruacan S. Struma ovarii. Int J Gynaecol Obstet 1993 Aug;42(2):143-146.

9. Costa MA, Povoa AM, Pires MC, Paiva VL, Pinto C, Martinez-de-Oliveira J. Struma ovarii: a rare form of presentation and clinical review. Acta Obstet Gynecol Scand 2005 Aug;84(8):819-820.

10. Ross DS. Syndromes of thyrotoxicosis with low radioactive iodine uptake. Endocrinol Metab Clin North Am 1998 Mar;27(1):169-185.

11. Matsuki M, Kaji Y, Matsuo M, Kobashi Y. Struma ovarii: MRI findings. Br J Radiol 2000 Jan;73(865):87-90.

12. Makani S, Kim W, Gaba AR. Struma ovarii with a focus of papillary thyroid cancer: a case report and review of the literature. Gynecol Oncol 2004 Sep;94(3):835-839. 